\title{
A Política de Quotas em Portugal: O papel dos partidos políticos e do feminismo de Estado
}

The Quota Policy in Portugal: The role of political parties and state feminism La politique de quotas au Portugal : le rôle des partis politiques et du féminisme d'État

Rosa Monteiro

\section{OpenEdition}

\section{Journals}

Edição electrónica

URL: http://journals.openedition.org/rccs/3953

DOl: $10.4000 /$ rccs.3953

ISSN: 2182-7435

Editora

Centro de Estudos Sociais da Universidade de Coimbra

Edição impressa

Data de publição: 1 Março 2011

Paginação: 31-50

ISSN: 0254-1106

\section{Refêrencia eletrónica}

Rosa Monteiro, «A Política de Quotas em Portugal: O papel dos partidos políticos e do feminismo de Estado », Revista Crítica de Ciências Sociais [Online], 92 | 2011, colocado online no dia 01 novembro 2012, criado a 30 abril 2019. URL : http://journals.openedition.org/rccs/3953 ; DOI : 10.4000/ rccs.3953 


\section{ROSA MONTEIRO}

\section{A Política de Quotas em Portugal: O papel dos partidos políticos e do feminismo de Estado}

A designada Lei da Paridade representa um marco importantíssimo na promoção da igualdade de mulheres e homens em Portugal. A sua relevância advém de vários factores, dentre os quais se destaca o seu impacto num sistema eleitoral que a inércia do sistema político-partidário tem sido incapaz de alterar. $\mathrm{Na}$ análise do surgimento das políticas de quotas em Portugal, o papel do principal mecanismo oficial para a igualdade, ou seja, da Comissão para a Cidadania e a Igualdade de Género, e das suas redes não tem sido estudado. Ora, como refere Mona Lena Krook, esforços para aumentar o número de mulheres em cargos políticos raramente acontecem na ausência de mobilização de mulheres. Adoptando a abordagem do feminismo de Estado, exploro aqui o papel da Comissão como uma entidade decisiva na apresentação das reivindicações feministas perante o Estado, um papel que tem sido sistematicamente ignorado, e explicito a forma como este mecanismo e as associações de mulheres em seu torno contribuíram para a promoção da agenda da participação das mulheres na política em Portugal.

Palavras-chave: Lei da Paridade, política de quotas, Comissão para a Igualdade de Género, igualdade de direitos, mulheres e política, Portugal.

\section{Introdução}

A questão da participação das mulheres na política apenas conheceu um avanço legislativo significativo, em Portugal, em 2006, com a designada "Lei da Paridade" (Lei Orgânica 3/2006, 21 de Agosto), que vincula uma representação de pelo menos $33 \%$ de ambos os sexos nas listas eleitorais para a Assembleia da República, para o Parlamento Europeu e para as autarquias locais. Ela resultou da aprovação do PL 224/X, do Partido Socialista (PS), tendo contado com os votos a favor do PS, abstenção do Bloco de Esquerda (BE) e votos contra do Partido Social Democrata (PSD), Centro Democrático Social (CDS), Partido Comunista Português (PCP) e Partido Ecologista os Verdes (PEV). Esta Lei, além de representar um marco importantíssimo na promoção da igualdade de mulheres e homens, 
é assinalável pela transformação que promove num sistema eleitoral que tem permanecido alheio a alterações, por inércia do sistema de interesses instalados (Cruz, 2000; Jalali, 2007).

Pretendo neste texto, além de reflectir sobre o significado de uma tal inovação legislativa, contribuir para a compreensão da complexidade na produção desta Lei, geralmente apresentada, de forma circunscrita à decisão, como um produto da acção do Partido Socialista. Isto porque me baseio numa concepção de políticas públicas que vai além da definição mais comum, por exemplo, de Mény e Thoenig (apud Dormagen e Mouchard, 2007: 230), de que são "os actos e não actos das autoridades públicas face a um problema relevante num determinado domínio". Na linha de interpolinização que liga os estudos dos movimentos sociais e as teorias neo-institucionalistas, no designado paradigma do processo político (McAdam, McCarthy e Zald, 1996; Snow, 2004; Tarrow, 1998), sigo o pressuposto de que as políticas de igualdade são resultado de uma complexa relação dinâmica de factores institucionais e estratégicos, de uma conjugação de actores complexos e multidimensionais, e não meramente produtos unilaterais de um ou de outro. Também na linha das novas definições de políticas públicas não circunscritas à decisão produzida, que reconhecem o papel de outros actores e suas redes (Peters e Pierre, 2006), considero aqui a "Lei da Paridade" como um produto diferido de reivindicações antigas, ainda que produto directo de proposta do PS, liderado por José Sócrates. A referida perspectiva busca a compreensão do processo no encadeado de acções ao longo do tempo, embora fuja às limitações das análises sequenciais (Cobb e Elder, 1972; Jones, 1970). Como refere Sarmento (2001), as novas abordagens na análise de políticas exploram e interpretam, também, as diversas cognições, sentidos e "quadros interpretativos" envolvidos nos debates e produtos políticos (Lombardo et al., 2009).

Proponho, portanto, analisar a "Lei da Paridade" de 2006, tradutora de uma política de quotas para a participação das mulheres na vida política, como um culminar de mais de 30 anos de reivindicações das representantes das mulheres portuguesas no principal mecanismo oficial para a igualdade e nos movimentos de mulheres e feministas portugueses, especialmente os departamentos de mulheres dos partidos políticos de esquerda. Adoptando a abordagem do feminismo de Estado (McBride e Mazur, 1995; 2005), exploro o papel do principal mecanismo oficial para a igualdade em Portugal como um portador decisivo das reivindicações feministas perante o Estado. Dado que o seu papel tem sido sistematicamente ignorado e não analisado, pretendo destacar e explicar a participação deste mecanismo oficial na discussão da agenda da paridade em Portugal, em articulação com a acção já 
mais analisada dos partidos políticos e movimentos de mulheres (Baum e Espírito-Santo, 2010; Freire e Baum, 2001; Jiménez, 2002; Tavares, 2008).

A actualmente designada Comissão para a Cidadania e Igualdade de Género (DL 164/200, de 3 de Maio) (doravante Comissão) veio suceder às suas antecessoras Comissão para a Igualdade e Direitos das Mulheres - CIDM (DL 166/91) - e Comissão da Condição Feminina - CCF (DL 485/77). Ela tem sido o mecanismo oficial para a igualdade com maior abrangência de mandato e longevidade, não obstante estas reestruturações. Tem sido também em seu torno que se têm constituído redes ou constelações cooperativas de mulheres $(\mathrm{Holli}, 2008)^{1}$ na reivindicação e implementação de políticas de igualdade.

A abordagem do feminismo de Estado explora efectivamente o papel dos mecanismos oficiais em articulação com os movimentos de mulheres na representação descritiva e substantiva das mulheres, consubstanciada na promoção de agendas e reivindicações políticas (McBride e Mazur, 2010). A compreensão da efectividade desta acção articulada faz intervir variáveis que se prendem não só com as estratégias prevalecentes dos movimentos e a sua coesão em torno de uma agenda política, com as características dos mecanismos oficiais, mas também e essencialmente com características do ambiente sociopolítico, designadamente as estruturas de oportunidades políticas, como a abertura e a existência de práticas de consulta, as viragens governativas, as atitudes dos principais partidos políticos, entre outras. Segundo a tipologia de Kitschelt (apud Hafner-Burton e Pollack, 2002), o sistema sociopolítico português apresentou, ao longo destes mais de 30 anos de democracia, estruturas de input pouco abertas às questões da igualdade de género e fracas estruturas de output (Monteiro, 2011). São já conhecidos os diagnósticos de um sistema democrático altamente centralizado e institucionalista, dominado por partidos, eles mesmo centralistas, constituídos por elites urbanas educadas, com fraquíssimo enraizamento social, mais mobilizados pelo assegurar cooperante das condições de "governabilidade" do que por uma política pluralista, aberta a projectos e a novos actores sociais (Aguiar, 1987; Ferreira, 2000; Freire e Baum, 2001; Jalali, 2007). Trata-se, portanto, de uma sociedade dualista e elitista, com uma sociedade civil frágil, com marcas persistentes de legados institucionais prévios à revolução democrática de 1974 (Aguiar, 1987; Santos, 1984).

\footnotetext{
${ }^{1}$ Relembre-se que a Comissão possui desde as suas primeiras formas, logo nos anos 1970, um organismo consultivo - o Conselho Consultivo -, constituído por duas Secções - a Interministerial e a das ONG. Este Conselho constituiu um importante espaço de institucionalização política e de articulação para os frágeis movimentos de mulheres e para os departamentos de mulheres de partidos políticos que pouco ou nenhum poder têm tido dentro das estruturas partidárias.
} 
A reflexão aqui apresentada resulta de uma pesquisa mais ampla de doutoramento ${ }^{2}$ sobre o feminismo de Estado em Portugal. A pesquisa empírica foi realizada com base num estudo de caso sobre a Comissão, que requereu uma abordagem qualitativa composta, em termos de fontes de investigação, pela realização de 53 entrevistas semi-estruturadas (a técnicos/as e ex-técnicos/as da Comissão, ex-presidentes e dirigentes da Comissão, responsáveis político/as da tutela, peritas, dirigentes de associações de mulheres, especialistas) e pela análise de material de arquivo (actas e documentos diversos), de legislação, publicações e artigos de imprensa.

Neste trabalho apresento em primeiro lugar a Lei e o seu significado no contexto português. Expõem-se também algumas das suas principais limitações e contestações. Em segundo lugar, reconstruo a trajectória de militância ou reivindicação em torno da agenda, destacando os protagonistas e seus motivos. Destaco particularmente o tipo de envolvimento da Comissão, procurando compreender factores relevantes face ao contexto sociopolítico. A participação da Comissão e suas redes na agenda da paridade será classificada de acordo com uma tipologia que estabeleci segundo quatro modalidades: insider, marginal, simbólica e ausente (Monteiro, 2011).

\section{A "Lei da Paridade": conteúdo e significado}

Ao contrário do reduzidíssimo diferencial de participação eleitoral, o diferencial de participação em cargos de decisão política é talvez aquele em que é mais flagrantemente visível a persistência da desigualdade sexual no nosso país. A participação eleitoral das mulheres tem registado aumentos entre a década de 1980 e 2002, não existindo actualmente qualquer diferença significativa entre a percentagem de homens e de mulheres que exercem o seu direito de voto (Baum e Espírito Santo, 2004). Porém, segundo dados de 2010, Portugal é ainda o 19..$^{\circ}$ país do mundo no que diz respeito à participação das mulheres em cargos ministeriais, e o $31 .^{\circ}$ relativamente à representação das mulheres no parlamento nacional. Nunca tivemos uma mulher como Presidente da República, apenas uma como Primeira-Ministra (de nomeação presidencial e durante somente 6 meses). O nível de representação de mulheres nos diversos governos, entre 1991 e 2009, só atingiu o seu pico mais alto (20\%) em 2002. Na Assembleia da República, as mulheres

\footnotetext{
${ }^{2}$ Doutoramento em Sociologia do Estado, Direito e da Administração, enquadrado pela Faculdade de Economia da Universidade de Coimbra e pelo Centro de Estudos Sociais e orientado pela Professora Doutora Virgínia Ferreira. A pesquisa beneficiou do apoio da FCT e deu origem à dissertação intitulada "Feminismo de Estado em Portugal: mecanismos, estratégias, políticas e metamorfoses".
} 
eram 23 em 1979 (8,3\%) e 64 em 2009 (27,8\%). No poder local, em 2009, as mulheres representavam apenas 7,5\% dos/as Presidentes de Câmara, a maioria em autarquias do PS. A nossa percentagem de deputadas europeias era de 36\% em 2009 (SIIC, 2010).

Antes da "Lei da Paridade", o PSD e o CDS eram os partidos que, tendo o menor número de deputadas, apresentavam os valores mais discrepantes relativamente aos restantes partidos, não ultrapassando os $8,3 \%$, comparativamente aos $50 \%$ do BE, $28,9 \%$ do PS, e $21,4 \%$ do PCP. Apesar da Lei, na XI Legislatura (2009-2011) nenhuma bancada atingiu os 33\% previstos na Lei, à excepção do BE (que reduziu a vantagem para $43,8 \%$ de deputadas), apesar de se ter assistido a um maior equilíbrio entre os partidos. Nas recentes eleições legislativas (2011) o número de mulheres eleitas desceu para $26,5 \%$. A CDU apresenta a menor proporção de mulheres (apenas 18\%) e o BE é mais uma vez a excepção, não só cumprindo mas ultrapassando o previsto na Lei, com $50 \%$ de mulheres nas suas bancadas. O CDS apresenta mais uma vez uma reduzida proporção de deputadas $(20,8 \%)$, o PSD supera o próprio PS com $28,7 \%$ de deputadas, contra os apenas $24,3 \%$ deste último 3 . Não deixa de ser decepcionante esta redução do número de deputadas eleitas pelo PS, dado o histórico do partido na promoção desta legislação. Estes números demonstram bem a hostilidade dos partidos com existência mais longa no nosso sistema à representação feminina, e expõem as debilidades da Lei aqui analisada.

Tal como acontece noutros países, o debate e a promoção de práticas acerca da representação política de mulheres desenvolveu-se essencialmente à esquerda do espectro político. ${ }^{4}$ Segundo Martins e Teixeira (2005), até 2005 o PCP e o PS foram os partidos que mais investiram na feminização das suas bancadas, sendo o BE (nascido em 1999) o mais progressista. Globalmente, os níveis de representação das mulheres estão ainda muito aquém do limiar considerado paritário, o que se explica pelas estratégias de selecção e recrutamento de pessoal no interior dos partidos. Isto explica também que, apesar do ténue aumento da feminização das listas, este não se venha traduzindo num aumento das eleitas, porque elas têm sido remetidas "pelo party selectorate para posições não elegíveis ou mais dificilmente elegíveis, protagonizando candidaturas mais simbólicas ou instrumentais do que efectivas" - entre 1991 e 2002, a percentagem de mulheres elegíveis era $15 \%$ e a de não elegíveis 22,4\% (Martins e Teixeira, 2005: 259). Sabe-se que o problema da participação das mulheres na vida política e nos

\footnotetext{
3 Sol (2011), "Mulheres nas listas não chegam à AR", 19.06.2011.

${ }^{4}$ Ressalve-se aqui a oposição persistente do PCP à introdução de quotas.
} 
partidos está do lado da procura, e que a "cultura organizativa predominante nos partidos constitui um dos principais factores condicionantes do processo de igualização de oportunidades de acesso ao poder e à tomada de decisão" (idem: 77).

A alteração desta situação de exclusão das mulheres, sendo consequência directa dos processos de recrutamento intrapartidários, tem estado dependente da vontade e acção dos partidos, já que são estes que têm a possibilidade de alterar os critérios de recrutamento, bem como de propor legislação que discipline as práticas partidárias. Como refere Krook, a adopção de sistemas de quotas "ilumina as práticas de recrutamento das elites políticas, indicando que os actores e as dinâmicas políticas, e não forças vagas de desenvolvimento, são o factor central na produção ou redução das desigualdades na representação política" (2009: 5). Ora em Portugal, do período pós-revolução para cá, o sistema eleitoral não tem sido sujeito a alterações ou revisões devido a uma certa inércia dos principais partidos e sistemas de interesses instalados (Jalali, 2007). O sistema eleitoral pós-revolução, que surgiu ainda antes da Constituição de 1976, é um sistema de representação proporcional, ${ }^{5}$ que utiliza o método D'Hondt para a atribuição de mandatos, com 22 círculos eleitorais. Ele antecedeu a configuração institucional do sistema democrático (Jalali, 2007), concretizando o objectivo de preservar as então frágeis democracia e estabilidade política. Fê-lo evitando maiorias monopartidárias e a possibilidade de chegada ao poder de pequenos partidos de esquerda radical, receada na altura pelos partidos dominantes ao centro. Por esta razão, Sá refere que este sistema eleitoral "tem na base os interesses dos partidos mais relevantes" (apud Jalali, 2007: 274), que o mantém como condição da sua própria subsistência.

A designada "Lei da Paridade" (Lei Orgânica 3/2006, 21 de Agosto) estabelece que "as listas para a Assembleia da República, para o Parlamento Europeu e para as autarquias locais são compostas de modo a assegurar a representação mínima de $33 \%$ de cada um dos sexos". Prevê também o designado sistema de fecho éclair, que consiste na obrigatoriedade de os partidos não colocarem mais de duas pessoas do mesmo sexo consecutivamente nas listas (o entendimento dominante foi o de que em cada 3 tem de haver pelo menos uma mulher).

Por ter proposto esta lei, o Partido Socialista recebeu, em 2009, uma distinção do Conselho da Europa - o Gender Equality Prize. O PS foi, aliás, o primeiro partido a promover debates e iniciativas parlamentares sobre esta

\footnotetext{
${ }^{5}$ Condição necessária à eficácia de um sistema de quotas.
} 
questão (em 1981, 1998, 2000 e 2006). Este partido tinha já, desde 1999, um sistema interno de quotas de $25 \%$, criado em 1988 mas implementado apenas em 1999, depois de chumbadas as suas propostas de o estender a todo o sistema político.

Portugal conhece, portanto, segundo a tipologia de Krook (2009), duas modalidades de políticas de quotas: o sistema de "quotas de partido", implementado voluntariamente pelo PS, em 1999, e que é o sistema mais comum em todo o mundo; e o sistema de "quotas legislativas", imposto a todos os partidos com a "Lei da Paridade", que é o tipo de política mais recente (década de 1990). A amplitude e impactos deste último são bastante maiores, implicando reformas nas leis eleitorais e constitucionais, graus de consenso entre os partidos, mudança de linguagem e formas de sanção das infracções. O seu maior impacto acontece em sistemas eleitorais de representação proporcional com listas fechadas e elevada amplitude dos círculos eleitorais distritais (Krook, 2009), como é o caso do sistema português (Jalali, 2007). A política de "quotas legislativas" é facilitada também nos casos em que o direito constitucional vigente reconhece as políticas de discriminação positiva (o que aconteceu na Revisão Constitucional de 1997), sem o que os opositores podem reclamar inconstitucionalidade (Valiente, 2005). Tal como é a tendência deste tipo de política, a Lei portuguesa adopta uma linguagem neutra, não falando explicitamente de mulheres, antes referindo a "representação mínima de 33,3\% de cada um dos sexos nas listas", ainda que vá além da indicação vaga de "facilitação de acesso" e prescreva quanto à colocação de candidatos/as nas listas.

A legislação portuguesa seguiu a tendência internacional da estratégia das "quotas legislativas" (Krook, 2009; Squires, 2007), particularmente recomendada na Plataforma de Acção de Pequim, e expandida na década de 1990. Naquela Plataforma, os Estados-membros eram aconselhados a tomarem medidas para assegurar o igual acesso e a plena participação das mulheres nas estruturas de poder, bem como a aumentar a capacidade das mulheres para participarem na decisão política (Krook, 2009). Sinal desta viragem como tendência pós-Pequim, designada na literatura como uma "febre de quotas" por todo o mundo (Squires, 2007: 10), é o facto de, só na década de 1990, terem aparecido sistemas de quotas em mais de 50 países (Krook, 2009). Mas não só as Nações Unidas apelaram à adopção de políticas de acção positiva; com efeito, naquela década, organizações como a Internacional Socialista, o Conselho da Europa, a União Europeia, entre outras, recomendaram uma representação de mulheres de pelo menos $30 \%$ em todos os órgãos políticos (Krook, 2009). O facto de terem aparecido em muitos países durante aquele período revela a importância deste factor 
- influência internacional - na adopção interna de políticas de quotas, ainda que possam ter sido matizadas pela acção de "empreendedores/as" ou "agentes de mudança” domésticos (Börzel e Risse, 2003). Elas são, portanto, um "fenómeno global" (Krook, 2009).

Um dos aspectos que maior crítica tem gerado na adopção deste modelo de políticas em Portugal tem a ver com a concepção de paridade que lhe subjaz, que a esmagadora maioria das pessoas entrevistadas entende ser limitada, por se restringir a uma "quota de $33 \%$ ", sendo "mais uma lei de quotas do que uma lei de paridade", como me foi referido nas entrevistas. Esta dissonância mantida agora na lei traduz um desacordo antigo, expresso na discussão de 1997-98 a propósito da proposta do PS, ${ }^{6}$ como revela o seguinte protesto da Comissão e de 40 ONG do seu CC:

Ao longo dos mais de vinte anos de actividade conjunta, as ONG de Defesa dos Direitos das Mulheres representadas no CC da CIDM têm desenvolvido uma acção permanente com vista ao aumento da participação política das mulheres. Todavia, confrontaram-se com um discurso de intenções político que sendo quase sempre favorável a este objectivo nunca se traduziu em alterações significativas do status quo. Assim sendo, a iniciativa legislativa do Governo introduz uma mudança qualitativa no tratamento político desta matéria que se entende ser de saudar [...].

Reafirmando a sua unanimidade em torno do conceito da paridade, tal como é definido pelo Conselho da Europa, as ONGM consideram que a proposta de lei em audição apenas serve parcialmente este conceito. Antes tratando-se de medida paliativa à sub-representação das mulheres, como se o poder político [...] estivesse dividido entre, por um lado, a sua má consciência de actor privilegiado do sistema e, por outro, os preconceitos dominantes. [...]

As ONGM entendem manifestar a sua enorme perplexidade, [...] e chamam a atenção para o mau serviç̧o que se presta ao debate generalizado na sociedade sobre o aperfeiçoamento da democracia, quando se recorre a uma terminologia consagrada, como "Democracia Paritária", para lhe atribuir uma definição errónea. (DAR 41S, 4.3.1999, sublinhado meu)

Este excerto, para além de revelar as denúncias de uma concepção "errada" e "limitada" de paridade, demonstra a aliança e coesão da Comissão e dos movimentos de mulheres do seu Conselho Consultivo na militância por esta causa.

\footnotetext{
${ }^{6}$ Que propunha uma quota de $33 \%$, mas uma meta intermédia de $25 \%$ na primeira eleição posterior à entrada em vigor da lei.
} 
Como noticiava a imprensa em 2009 (ano de 3 actos eleitorais, "prova de fogo" da Lei), a "Lei da Paridade" foi particularmente difícil de cumprir nas listas das eleições autárquicas, onde todos os partidos a violaram, ainda que uns com maior expressão, sujeitando-se aos cortes de subsídios previstos como sanção ${ }^{7}$ (Santos, 2010). Apesar dos diversos balanços e do cumprimento da Lei que alterou os rostos da propaganda político-partidária nesse ano, o facto é que a Lei não foi suficiente para alterar de forma significativa a composição dos principais órgãos de poder (SIIC, 2010). Alguns balanços dos impactos da Lei destacam as suas limitações ou instrumentalizações por conveniência do status quo partidário. Com efeito, por um lado, o facto de grande parte das mulheres ter sido colocada em terceiro lugar nas listas responde pelas diferenças de poder dos cargos a que concorrem e pelas menores possibilidades de eleição. Por outro lado, o facto de a Lei ser omissa quanto à possibilidade de, depois de eleitas, as candidatas poderem renunciar e serem substituídas por homens, permite comportamentos condenáveis, como foi denunciado na Madeira e em Famalicão. ${ }^{8}$ Ainda assim, e como identificou Maria Helena Santos (2010), destaca-se o optimismo global acerca dos efeitos da Lei, reconhecendo-se que as percentagens atingidas em 2009 são já um seu reflexo.

\section{Comissão: uma aliada simbólica esquecida entre os protagonistas}

$\mathrm{Na}$ análise do surgimento das políticas de quotas em Portugal, o papel da Comissão e das suas redes não tem sido estudado. Michael Baum e Ana Espírito Santo (2010) exploram a acção de quatro tipos de actores - sociedade civil (media e opinion makers), actores do Estado (partidos e Presidente da República), actores internacionais e transnacionais (partidos transnacionais e organizações europeias) e contexto político (opinião pública e sistema eleitoral). Concluem, por exemplo, que em 2006, os meios de comunicação social foram mais favoráveis à temática, estrategicamente apresentada como "paridade" e não como "quotas". Destacam também uma opinião pública mais favorável às quotas em 2006. Consideram que o papel das ONG não foi crucial no debate, apresentando como factor decisivo o próprio Partido Socialista e suas elites (Baum e Espírito-Santo, 2010). Deixam, portanto,

\footnotetext{
7 Ver "Autárquicas: Lei da Paridade violada por quase todos os partidos em todo o país", Público, 12.9.2009.

8 Ver "Lei da Paridade não fecha portas à discriminação: Polémica já rebentou em Famalicão", Público, 13.11.2009.

9 A integração dos partidos políticos na categoria de actores estatais é uma opção dos investigadores que não segue a proposta em que se baseia, que os inclui na categoria de actores da sociedade civil (Krook, 2009: 29). Krook inclui na categoria de actores estatais a estudar nas "campanhas das quotas" os mecanismos oficiais para a igualdade (2009).
} 
por explorar o papel de activistas da Comissão ou a ela ligadas em todo o desenvolvimento desta agenda política anterior à Lei de 2006, inclusivamente no lobby pelas quotas internas no PS.

Como refere Mona Lena Krook (2009: 21), esforços para aumentar o número de mulheres em cargos políticos raramente acontecem na ausência de mobilização de mulheres. Ela reconhece que o activismo das mulheres só é considerado quando um líder masculino bem posicionado no partido abraça também a causa e a promove internamente, mas lembra que é decisivo que exista pressão por parte das mulheres (dentro ou fora dos partidos, dentro ou fora do Estado) para que se dêem passos significativos. Por isso, Krook afirma que o papel dos movimentos de mulheres e dos mecanismos oficiais para a igualdade é neste tipo de agenda bem mais complexo e por vezes diferido do que noutras questões - por um lado, ele é ocultado pelo protagonismo do partido e dos seus líderes masculinos, que apresentam as propostas; por outro, só quando estes líderes chegam ao poder é que o trabalho feito anteriormente se traduz em resultados. Foi exactamente isto que aconteceu em Portugal, sendo a Comissão e as suas redes de mulheres as ilustres esquecidas nos louros desta agenda. O seu papel foi um papel que designo por simbólico, persistente embora de impactos pouco reconhecidos desde a década de 1980 (Monteiro, 2011).

Apesar de particularmente mediática a partir da discussão de 1998, o que se espelhou num aumento tímido da feminização da representação parlamentar nos partidos, e num efeito de contaminação e de mimetismo eleitoralista (Martins e Teixeira, 2005), o facto é que a reivindicação da participação das mulheres nas estruturas de decisão política começou muito antes. Ela conheceu episódios significativos já na década de 1980 e mesmo antes disso, nomeadamente pela acção de mulheres ligadas à Comissão, a ONG e a departamentos de partidos políticos representados no seu Conselho Consultivo. Apenas a título de exemplo, foi a CCF que lançou em 1988 o debate sobre as políticas de acção positiva, assumindo assim um papel decisivo na tradução interna deste tipo de política de igualdade internacionalmente dimanada. Nesse mesmo ano, propôs, ainda que sem sucesso, a inclusão das acções positivas na Revisão Constitucional. Apenas no PS, Ana Coucello e Maria Alzira Lemos (representantes do Departamento de Mulheres do partido no CC da Comissão) conseguiram introduzir o debate, como revela o seguinte excerto de entrevista:

[...] uma das primeiras coisas que nós fizemos nesse Conselho do Departamento de Mulheres foi um seminário, que foi a plataforma de lançamento da disposição estatutária sobre as quotas, chamado "Que lugar para as mulheres nos partidos políticos?". 
Foi em 87, eu queria chamar ao seminário "Há lugar para as mulheres nos partidos políticos?” mas a Maria Alzira Lemos disse que era melhor não sermos tão agressivas e sugeriu "Que lugar para as mulheres". (ent. Ana Coucello)

Não se pode, pois, ignorar o muito trabalho desenvolvido, ainda que aquelas mulheres e instituições não tenham participado directamente em todos os debates e na produção da legislação (à excepção do debate de 1997-98), e que os efeitos desse trabalho tenham sido diferidos. A questão da participação política das mulheres foi uma luta de mulheres que se movimentaram entre a Comissão, as ONG e especialmente o Partido Socialista (mulheres que têm o que designo por múltiplas pertenças),${ }^{10}$ como descrito nas entrevistas:

Foi bastante consensual, porque era uma coisa que vinha a ser trabalhada. Portanto, quando surge a primeira proposta na Assembleia da República já havia alguns anos de trabalho naquela área, já tinham sido feitas aquelas coisas todas, os seminários, os encontros autárquicos, o parlamento paritário [...]

[...] As audições no parlamento, o que nós levámos para as audições, o que fomos dizer nas audições, o trabalho que foi feito, o trabalho que as mulheres fizeram nos partidos políticos. (ent.8, ex-representante de associações de mulheres)

Explorando os factores que contribuem para esta invisibilidade da contribuição do feminismo de Estado, desde logo se encontra o facto de nos partidos serem geralmente os líderes masculinos a apresentar a maioria das propostas importantes (Baum e Espírito-Santo, 2010), ocultando a influência feminina e as suas redes, que têm um carácter disperso, pouco visível ou reconhecível.

Considero que um outro factor tem contribuído para essa invisibilização: o pouco poder das mulheres dos departamentos de mulheres dos partidos em Portugal. Ao contrário do Partido Socialista Operário Espanhol (PSOE), onde as mulheres do Instituto de la Mujer que pertenciam ao partido tinham posições de poder dentro dele, e as suas vozes foram bastante ouvidas e reconhecidas, falando-se mesmo de um forte "feminismo de partido" (Arnedo, 2009; Threlfall, 2009; Valiente, 2005), no PS português nenhuma presidente do seu departamento de mulheres teve alguma vez algum cargo político importante; mesmo as presidentes das Comissões Parlamentares para a igualdade em representação do PS

${ }^{10}$ Um dos casos mais salientes desta múltipla pertença foi o de Alzira Lemos, representante das mulheres do PS no CC, técnica da Comissão durante algum tempo, fundadora e dirigente de associações de mulheres (Intervenção Feminina) para as questões da paridade. 
(Teresa Ambrósio, Julieta Sampaio, Rosário Carneiro) não eram figuras de muito poder no partido. Ao contrário do espanhol, o departamento de mulheres do PS não foi nunca forte, mas antes mantido em resposta a uma exigência da Internacional Socialista, conforme me foi dito nas entrevistas. A comparação com Espanha é interessante, porque apesar de terem existido relações igualmente intensas entre as mulheres do mecanismo oficial e algumas activistas do partido, cá, ao contrário de lá, estas alianças eram alianças de "excluídas", ao passo que lá, mulheres como Carlota Bustelo eram poderosas e proporcionaram alianças fortes e canais fortes e influentes para dentro do PSOE. Cá, as mulheres do departamento parecem ter tido um espaço decisivo de militância na Comissão, ao nível do Conselho Consultivo e das ONG que criaram em torno dele, como é o caso já mencionado de Maria Alzira Lemos e de Ana Coucello. Ora isto confirma algumas teses sobre a fraqueza dos departamentos de mulheres e o facto de que não é a pertença a um que confere às mulheres maior capacidade política nos partidos portugueses (Jiménez, 2009), apesar de na literatura isso ser apontado como uma vantagem noutros países (Lovenduski, 1993).

Justificada a sua pouca visibilidade, demonstro de seguida como nesta agenda da paridade a Comissão teve uma "acção simbólica" fundamental, já que ao longo do tempo ela procurou, através de debates, publicações e outras acções, re-significar, reinterpretar, reformular as normas e as práticas da sociedade e do Estado. Nas entrevistas realizadas, a "agenda da democracia paritária" foi apontada como a agenda mais consensual entre Comissão e a secção das ONG do seu Conselho Consultivo. Esta coesão, se não se traduziu imediatamente em ganhos políticos satisfatórios, facilitou e muito a adopção das medidas legislativas que hoje são conhecidas, e levou a um maior reconhecimento social da necessidade de uma intervenção neste domínio. A Comissão, com as suas constelações cooperativas de mulheres, especialmente as ligadas a partidos, foi o epicentro das reivindicações pela democracia paritária em Portugal. Por acção ou participação simbólica refiro-me às agendas nas quais a acção da Comissão foi mais notória pela persistência de acção educativa e de sensibilização da sociedade e dos actores políticos, através da linguagem e da reinterpretação, veiculadas fundamentalmente por conferências, debates e publicações com impacto político diferido no tempo (Monteiro, 2011). Assemelha-se ao que Beckwith (2007) designa por política discursiva, baseada na reiterada exposição da situação política das mulheres e de um esforço para mudar o universo do discurso político das instituições.

Que acção simbólica foi esta? $\mathrm{Na}$ análise que realizei, emergem dois tipos de estratégia para a promoção da igualdade na participação política de mulheres e homens: uma baseou-se na produção e divulgação de informação 
sobre a matéria; a outra, no trabalho com redes e na constituição de constelações cooperativas, que teve como epicentro a Secção das ONG do CC e até mesmo a criação de novas $\mathrm{ONG}$ na sequência de dinâmicas daquela Secção.

O número de publicações da Comissão em torno da questão foi significativo - cerca de 15 títulos; os seminários e encontros, nos quais participavam representantes dos partidos, foram também um importante palco para a introdução das questões da democracia paritária e das políticas de acção positiva, em tradução da normatividade e das recomendações internacionais, assumindo-se estas mulheres como "empreendedoras de normas" (Börzel e Risse, 2003). Logo em 1987-88, a Comissão propôs, sem sucesso, incluir na revisão Constitucional o reconhecimento das acções positivas (que divulgou), o que só viria a acontecer em $1997 .{ }^{11}$ Destaque-se aqui o facto de várias técnicas da Comissão e mulheres com assento no CC em representação de associações terem uma presença assídua nas redes de feminismo transnacional institucionais (Conselho da Europa ${ }^{12}$ e não institucionais (LEM), o que favoreceu a sua acção interna.

A constituição de redes ou constelações cooperativas foi outra das estratégias. Desde os anos 1980 a Comissão introduziu a temática no seu trabalho interno e no CC, tendo-se tornado uma agenda de grande prioridade, ao que não será alheia a importância que tiveram os departamentos de mulheres dos partidos políticos naquela plataforma institucional que foi a principal estrutura de mobilização das associações de mulheres portuguesas - a secção de ONG do CC da Comissão (Tavares, 2008). Para além da presença dos departamentos de mulheres dos partidos políticos, criaram-se em torno do CC quatro ONG dedicadas a esta matéria: Intervenção Feminina; Associação Convergência; Aliança para a Democracia Paritária ${ }^{13}$ e Rede de Mulheres Autarcas (REMA). Em 1993, naquela Secção criou-se o Grupo de Trabalho para a Democracia Paritária - que viria a ser um dos mais dinâmicos. As suas primeiras iniciativas foram debates com representantes dos partidos e responsáveis de "estruturas de mulheres" dos partidos. Vejamos como são descritas estas dinâmicas conjuntas:

Até porque em fins dos anos 1980 é quando o Conselho da Europa assume o conceito de paridade definido por Claudette Apprill, e apoiado e desenvolvido por Regina

\footnotetext{
${ }_{11}$ Refira-se que na Revisão Constitucional de 1997, nomeadamente na discussão do art. ${ }^{\circ} 109$ (acções positivas), a Comissão foi ouvida, tendo as suas técnicas reunido com deputados, e foram também ouvidas representantes da Associação Portuguesa de Mulheres Juristas e das Mulheres Socialistas. 12 Regina Tavares da Silva, por exemplo, foi presidente do Grupo de Trabalho para a Democracia Paritária do Conselho da Europa (1991-93).

13 Esta foi criada por mulheres da Comissão e por representantes do Partido Socialista, por exemplo.
} 
Tavares da Silva, à época Presidente do CDEG. E portanto a Regina lançou ao Conselho Consultivo um desafio que era a divulgação do conceito em Portugal, e eu senti logo que aquilo podia ser um instrumento muito importante [...]

A agenda da paridade entra por aí e então eu apoio a criação na Secção das ONG de um Grupo de Trabalho da Democracia Paritária [...]. (ent.8, ex-representante de associações de mulheres)

Estas redes reivindicaram reformas aos partidos e aos governos; em 1997 exigiram que se cumprisse o disposto na Constituição de 1997 em matéria de acções positivas, que constituía assim uma estrutura de oportunidades políticas que a Comissão quis aproveitar..$^{14}$ Apesar de insatisfatória, a Comissão conseguiu pela primeira vez uma resposta da parte do Estado à sua agenda da participação das mulheres na vida política, já que este tomou uma iniciativa legislativa na sequência das suas reivindicações, e ela foi ouvida nas discussões na Assembleia da República. Mas segundo a tipologia de McBride e Mazur (2005), a resposta do Estado foi de cooptação,$^{15}$ uma vez que, por um lado, a proposta do PS não correspondeu à definição desejada do "limiar de paridade" dos 40\% (Conselho da Europa), e por outro, a proposta foi chumbada no Parlamento.

Sendo a Assembleia da República e os partidos estruturas de oportunidades políticas relativamente fechadas aos actores do feminismo de Estado portugueses, e sendo a própria questão da paridade na política uma área com uma estrutura de input fechada, onde os partidos têm o protagonismo e a centralidade na discussão (Lovenduski, 2005), a existência destas redes de mulheres com ligações aos partidos e à Assembleia proporcionou canais de influência importantes para a Comissão, embora não suficientes para um sucesso. Nomeadamente, as Comissões Parlamentares para a igualdade, bem como o desenvolvimento de redes ligadas aos partidos políticos, são formas de os mecanismos oficiais estabelecerem pontos de acesso àqueles espaços, e isso foi o que aconteceu em Portugal para a introdução das políticas de acção positiva, como foi possível verificar em 1997-98, por exemplo, com as

\footnotetext{
${ }^{14}$ A possibilidade constitucional para as acções positivas vinha sendo reclamada pela Comissão desde 1989, como se viu acima, e voltou a ser reclamada em 1995, argumentada desta vez com os desenvolvimentos e a normativa internacional, em especial a Plataforma de Acção da Conferência Mundial de Pequim (1995), a Declaração de Atenas (aprovada pela AR em 1993), a Carta de Roma (1996), o IV Programa Comunitário sobre Igualdade de Oportunidades entre Mulheres e Homens (1996-2000) e o Tratado de Amesterdão (1997), que ampliava os compromissos dos Estados no combate às discriminações.

${ }^{15}$ Quando existe representação descritiva, mas não substantiva, no processo de decisão política, ou seja, quando as representantes das mulheres participam no processo, mas o resultado não integra ou segue as suas propostas.
} 
audições promovidas pela Comissão Parlamentar para a Paridade, Igualdade de Oportunidades e Família. Tendo em conta os resultados, conclui-se, no entanto, que estas alianças informais, apesar de importantes, não deixam de ser "alianças de excluídas", como lhes chamei, comprovando a fragilidade e carácter marginal dos "triângulos de veludo" (Woodward, 2003) face aos triângulos, esses sim "de ferro", dos partidos.

Paralelamente à tecitura de rede, a Comissão agiu de forma muito intensa em processos de socialização/educação para a "democracia paritária", quer dos agentes político-partidários, quer da sociedade em geral, embora a resposta do Estado tenha sido de cooptação (1997-98), primeiro, e depois de apropriação ${ }^{16}$ (2006).

A política de acções positivas ou de quotas foi, portanto, uma política que entrou com dificuldade nos quadros interpretativos dominantes, por isso foi rejeitada até 2006. A sociedade e sistema político portugueses não foram condutores desta política dado o seu carácter polémico. Da parte de alguma esquerda, é considerada liberal, não anulando a desigualdade de classe na base da política (como tem contra-argumentado o PCP). Da parte da direita, prevalecia argumentação meritocrática.

\section{Conclusão}

A agenda política da paridade confrontou as representantes das mulheres portuguesas com um sistema e com actores que foram globalmente pouco abertos e pouco condutores das suas reivindicações. Destacam-se em especial os partidos políticos, já que a eles se dirigiram as reivindicações, dada a sua centralidade na discussão das questões.

No estudo que fiz sobre feminismo de Estado em Portugal (Monteiro, 2011) concluí, com efeito, que os partidos e a Assembleia da República são espaços que apresentam estruturas de oportunidades políticas mais fechadas à intervenção de actores como os do feminismo de Estado, porque dominados por elites masculinas, pelo reduzido peso e poder dos departamentos de mulheres dos partidos, pelo centralismo do seu modelo de decisão política. Concluí também que, globalmente, o Estado português é um Estado centralista, elitista e juridista (Aguiar, 1987; Cardoso, 2000; Ferreira, 2000; Santos, 1993), que concedeu à Comissão e às questões das mulheres um estatuto essencialmente marginal, e que por isso os poucos sucessos em matéria de políticas de igualdade resultaram mais das estratégias informais das técnicas da Comissão e suas redes, que se assumiram como agentes de tradução da

${ }_{16}$ Acontece quando o Estado não inclui as representantes das mulheres no processo, mas dá alguma satisfação política (McBride e Mazur, 2005). 
normatividade internacional para os resistentes ou pouco crentes agentes políticos nacionais.

$\mathrm{Na}$ ausência de importantes vozes internas (departamentos de mulheres) e de pressão externa, dados os frágeis movimentos de mulheres e a indiferença às desigualdades em razão do sexo que caracterizam a sociedade em geral (Ferreira, 2000), os partidos não têm sentido pressão para legislar e intervir com assertividade e premência. Até porque a matéria da igualdade de mulheres e homens não é percebida como um trunfo de competição eleitoral, como Jiménez $(2002 ; 2009)$ constatou por contraste com a situação espanhola.

A agenda da paridade, em especial a questão do sistema de quotas, é, pela sua natureza, afrontadora do status quo dominante, sexualizando necessariamente os debates em seu torno, por isso ela foi mediática e polémica numa sociedade amplamente insensível às desigualdades sexuais (Ferreira, 2011). Ela reclama a cedência do poder masculino nos partidos e na política, visibiliza a especificidade da situação feminina na sociedade e questiona argumentos meritocráticos.

Tudo isto justifica 30 anos de demora até à obtenção em 2006 de um primeiro resultado satisfatório. Depois de todo este tempo, a viragem de alinhamentos políticos para um governo de maioria do Partido Socialista (XVII Governo Constitucional) proporcionou a estrutura de oportunidades políticas necessária, confirmando a tese de que as viragens governativas à esquerda são mais favoráveis às reivindicações feministas (Lovenduski, 2007; McBride e Mazur, 1995; Sawer, 2007; Valiente, 2007). Alguns estudos centram-se na procura de explicações para esta decisão do PS, avançando motivos como a sua evolução ideológica, a emulação transnacional, a competição eleitoral à esquerda com o $\mathrm{BE}$ e a sua liderança (Baum e Espírito Santo, 2010). Nas entrevistas que realizei, captei outro factor que se prende com uma atitude mimética relativamente ao PSOE e a Zapatero, que surgem assim como modelos para José Sócrates nestas matérias. É claro que o facto de o XVII Governo ter sido o primeiro governo de maioria absoluta do PS deve ser tido também como facilitador.

Este resultado diferido confirma também a já referida ideia de Krook (2009) de que o papel do feminismo de Estado é neste tipo de agenda bem mais complexo, diferido e invisibilizado. Isto devido ao protagonismo dos partidos e dos seus líderes masculinos na apresentação das propostas, e porque só quando estes líderes aliados chegam ao poder é que o trabalho feito para trás se traduz em resultados. Em Portugal, e ao contrário do que alguns estudos muito focalizados na "Lei da Paridade" parecem apontar, a mobilização das mulheres em articulação com os desenvolvimentos 
internacionais precedeu e foi bem mais sistemática do que a acção dos partidos nesta questão da representação política. Tal como outros estudos que têm destacado a importância de mulheres e suas reivindicações na produção destas legislações paritárias (Lovenduski, 1993; Jiménez, 2002), pretendi aqui dar visibilidade à acção da Comissão e redes de mulheres no lobby por medidas de acção positiva, na sensibilização dos agentes políticos e sociais e na tradução das recomendações internacionais (Börzel e Risse, 2003). A sua acção simbólica foi decisiva na divulgação e socialização de agentes políticos e sociedade. A pertença e participação de técnicas da Comissão e de representantes das ONG e dos partidos em redes transnacionais de advocacy, como o Conselho da Europa, a UNESCO, a Comissão Europeia, a Conferência Mundial de Pequim, o LEM, entre outras, revelaram-se decisivas no seu trabalho de advocacy interno.

No caso da paridade, a Comissão foi uma forte aliada simbólica, envolvendo-se intensa e sistematicamente na sua promoção, pela educação e tradução da normatividade internacional das políticas de acção positiva junto dos agentes políticos. Os movimentos de mulheres aceitaram esta agenda de forma consensual, dedicando-lhe importante fatia do seu trabalho conjunto na plataforma institucional (a Secção de ONG do CC da Comissão) e no lobby junto dos partidos. O canal ou estrutura de mobilização privilegiada foi, portanto a institucional (o CC da Comissão), e a ligação, muitas vezes informal, aos partidos.

Uma conclusão final, porém, deve reflectir sobre as dificuldades. Não obstante a presença destes factores potenciadores de sucesso (intensa acção do mecanismo oficial, coesão dos movimentos de mulheres), desde a década de 1980, percebe-se que, mais do que as atitudes e formas de articulação da Comissão e dos movimentos de mulheres, o que foi decisivo no desencadear de resultados legislativos significativos foi a atitude do partido político no poder, neste caso o PS, que funcionou como aliado. Como estipulam as teses do feminismo de Estado, mais do que as características dos mecanismos oficiais e dos movimentos de mulheres, parece que também em Portugal os dados estruturais e conjunturais do sistema político-institucional prevalecem na explicação de resultados nas políticas de igualdade. Esta conclusão aponta também para a limitada efectividade do feminismo de Estado na conquista de resultados políticos significativos em Portugal, apesar da sua longa e intensa história. 


\section{Referências bibliográficas}

Aguiar, Joaquim (1987), "Formas de dominação e sociedade: o caso do neo-patrimonialismo”, Análise Social, XXIII (96), 241-278.

Arnedo, Elena (2009), "Mujer y Socialismo”, in Carmen M. Ten, Purificación G. López e Pilar G. Ruiz (orgs.), El Movimiento Feminista en España en los años 70. Madrid: Cátedra, 219-245.

Baum, Michael; Espírito-Santo, Ana (2004), “A participação feminina em Portugal numa perspectiva longitudinal”, comunicação apresentada no $V$ Congresso Português de Sociologia, Braga, 12-15 de Maio. Disponível em http://www.aps.pt/cms/docs_prv/ docs/DPR4628d29527197_1.pdf, consultado a 30.6. 2007.

Baum, Michael; Espírito-Santo, Ana (2010) "Portugal's 2006 Quota/Parity Law: An Analysis of the causes for its adoption”, comunicação apresentada no colóquio "Gender Parity and Quotas in European Politics: A symposium for West European Politics".

Beckwith, Karen (2007), “Mapping Strategic Engagements: Women's movements and the state", International Feminist Journal of Politics, 9 (3), 312-338.

Börzel, Tanja; Risse, Thomas (2003), "Conceptualizing the Domestic Impact of Europe”, in K. Featherstone e C. Radaelli (orgs.), The Politics of Europeanisation. Oxford: Oxford University Press, 57-80.

Cardoso, João Casqueira (2000), “O projecto 'prever o impacto das políticas': pressupostos e principais pontos”, ex-aequo, 2/3, 75-91.

Cobb, Roger W.; Elder, Charles D. (1972), Participation in American Politics. The Dynamics of Agenda Building. Baltimore: Johns Hopkins U. P.

Cruz, Manuel Braga da (2000), "A revisão falhada do sistema eleitoral”, Análise Social, XXXV, 45-53.

Dormagen; Jean-Yves; Mouchard, Daniel (2007), Introduction à la sociologie politique. Bruxelas: DeBoeck.

Ferreira, Virgínia (2000), "Sexualizando Portugal: mudança social, políticas estatais e mobilização das mulheres”, in António C. Pinto (org.), Portugal contemporâneo. Palo Alto: TSPSS, 180-212.

Ferreira, Virgínia (2011), "Engendering Portugal: Social Change, State Politics and Women's Social Mobilization”, in António C. Pinto (org.), Contemporary Portugal. 2nd ed. Social Science Monographs. New York: Columbia University Press, 153-192.

Freire, André; Baum, Michael (2001), "Partidos políticos, movimentos de cidadãos e referendos em Portugal: os casos do aborto e da regionalização”, Análise Social, XXXVI, 9-41.

Hafner-Burton, Emilie; Pollack, Mark A. (2002), "Mainstreaming Gender in Global Governance”, European Journal of International Relations, 8(3), 339-373.

Holli, Anne Maria (2008), "Feminist Triangles: A conceptual analysis”, Representation 44 (2), 169-85. 
Jalali, Carlos (2007), Partidos e Democracia em Portugal 1974-2005. Lisboa: ICS.

Jiménez, Antonia Maria Ruiz (2002), Mecanísmos del cambio ideológico e introducción de políticas de género en partidos conservadores: el caso de Ap-Pp en España en perspectiva comparada. Madrid: Instituto Juan March.

Jiménez, Antonia Maria Ruiz (2009), "Women and Decision-making Participation within Rightist Parties in Portugal and Spain”, Análise Social vol. XLIV (191), 2009, 235-263.

Jones, Charles (1970), An Introduction to the Study of Public Policy. Belmont: Wadsworth.

Krook, Mona L. (2009), Quotas for Women in Politics: Gender and candidate selection reform worldwide. Oxford: Oxford University Press.

Lombardo, Emanuela; Meier, Petra; Verloo, Mieke (2009), The Discursive Politics of Gender Equality: Stretching, bending and policy-making. London: Routledge.

Lovenduski, Joni (1993) "Introduction: The dynamics of gender and party", in Joni Lovenduski e Pippa Norris (orgs.), Gender and Party Politics. London: Sage, 1-15.

Lovenduski, Joni (2005), "Introduction: State feminism and the political representation of women”, in J. Lovenduski (org.), State Feminism and Political Representation. Cambridge: Cambridge University Press, 1-19.

Lovenduski, Joni (2007), "Unfinished Business: Equality policy and the changing context of state feminism in Great Britain”, in Joyce Outshoorn e Johanna Kantola (orgs.), Changing State Feminism. Basingstoke: Palgrave MacMillan, 144-163.

Martins, Manuel; Teixeira, Conceição (2005), O funcionamento dos partidos e a participação das mulheres na vida política e partidária em Portugal. Lisboa: CIDM.

McAdam, Doug; McCarthy, John; Zald, Mayer N. (1996), "Introduction: Opportunities, mobilizing structures, and framing processes - toward a synthetic, comparative perspective on social movements", in Doug McAdam; John D. McCarthy; Mayer N. Zald (orgs.), Comparative Perspectives on Social Movements: Political opportunities, mobilizing structures, and cultural framings. New York: Cambridge University Press, 1-20.

McBride, Dorothy; Mazur, Amy (orgs.) (1995), Comparative State Feminism. Thousand Oaks, CA: Sage.

McBride, Dorothy; Mazur, Amy (2005), RNGS Project Description 5/05, disponível em http://libarts.wsu.edu/polisci/rngs/pdf/project505.pdf, consultado em 8.8.2008.

McBride, Dorothy; Mazur, Amy (2010), The Politics of State Feminism: Innovation in comparative research. Filadélfia: Temple Univ. Press.

Monteiro, Rosa (2011), Feminismo de Estado em Portugal: mecanismos, estratégias, políticas e metamorfoses. Tese de doutoramento apresentada à FEUC/CES.

Peters, Guy; Pierre, Jon (orgs.) (2006), Handbook of Public Policy. London: Sage.

Santos, Maria Helena (2010), Género e política: factores explicativos das resistências à igualdade. Tese de doutoramento, ISCTE-IUL.

Santos, Boaventura de Sousa (1993), "O Estado, as relações salariais e o bem-estar social na semi-periferia: o caso português”, in Boaventura de S. Santos (org.), Portugal: um retrato singular. Porto: Afrontamento,15-56. 
Santos, Boaventura de Sousa (1984), “A Crise e a reconstituição do Estado em Portugal (1974-1984)”, Revista Crítica de Ciências Sociais, 14, 7-29.

Sarmento, Cristina M. (2001), "Políticas públicas: o espelho da política, conjecturas de ordem”, in A Reforma do Estado em Portugal - Problemas e Perspectivas. Lisboa: Bizâncio, 641-658.

Sawer, Marian (2007), "Australia: the Fall of the Femocrat", in Joyce Outshoorn e Johanna Kantola (orgs.), Changing State Feminism. Basingstoke: Palgrave Macmillan, 20-40.

SIIC (2010), "Relatório: igualdade de género e tomada de decisão; violência contra as mulheres, doméstica e de género". Consultado em http://www.igualdade.gov.pt/ index.php/pt/documentacao/relatorios/552-20100518-siic, a 10.10.2010.

Snow, David (2004), "Framing Processes, Ideology, and Discursive Fields", in David A. Snow, Sahra A. Soule e Hanspeter Kriesi (orgs.), The Blackwell Companion to Social Movements. Oxford: Blackwell, 380-412.

Squires, Judith (2007), The New Politics of Gender Equality. New York: Palgrave.

Tarrow, Sidney (1998), Power in Movement: Social movements and contentious politics. Cambridge: Cambridge University Press.

Tavares, Manuela (2008), Feminismos em Portugal (1947-2007). Tese de Doutoramento apresentada à Universidade Aberta.

Threlfall, Mónica (2009), "El poder transformador del movimiento de mujeres en la transición política española”, in Carmen M. Ten, Purificación G. López e Pilar G. Ruiz (orgs.), El movimiento feminista en España en los años 70. Madrid: Cátedra, 17-52.

Valiente, Celia (2007), "Developing Countries and New Democracies Matter: An overview of research on State Feminism worldwide”, Politics E Gender 3(4), 530-541.

Valiente, Celia (2005), “The Women's Movement, Gender Equality Agencies and Central-state Debates on Political Representation in Spain”, in Joni Lovenduski (org.), State Feminism and Political Representation. Cambridge: Cambridge University Press, 174-194.

Woodward, Alison (2003), "European Gender Mainstreaming: Promises and pitfalls of transformative policy”, The Review of Policy Research, 20(1), 65-88. 